\title{
Machine Learning for Healthcare Diagnostics
}

\author{
Tata Sutabri, R. Pandi Selvam, K. Shankar, Phong Thanh Nguyen, Wahidah Hashim, Andino \\ Maseleno
}

\begin{abstract}
Presently machine learning and artificial intelligence is playing one of the most important role in diagnose many genetic and non genetic disease. So that the rapid inventions in machine learning can save thousands of life's as it can diagnose the early stage of many serious diseases. In this research the datasets for such diseases is studied and it will be analyzed that how such deep machine learning will impact to a human life. The problem with such methodology is that it is not possible to get accurate results in the initial stage of research. The reason is every human have different immunity power and stamina. There are many diagnostics center who are fully dependent on the equipments which are fully based on machine learning. In order to boost this process it is necessary to collect the real time patient's data from different hospitals, states and countries. So that it will be beneficial for world wide.
\end{abstract}

Keywords : health sevices; Treatment Recommender ; complementary tools.

\section{INTRODUCTION}

The government in many countries is promoting such activities so that it helps in greater development in such methodologies. The use of computer and artificial intelligence helps to diagnose quickly and in a optimum way. The previous researches datasets helps to improve the result. Learning from previous results or datasets and improvement in diagnose is known as deep learning. Deep learning is one of the most beautiful part of machine learning. For example, just assume a newly started research in machine learning is as a new born child.

Initially just like a new born child the machine learning research in initial stage knows nothing. But after providing datasets day by day, it will start perform better and also will provide the better results. The computer system who are using machine learning system are capable to process and produce a big amount of medical data also they can produce the real time results accordingly. Which is not possible by a physician? The issue with such procedure is that it is absurd

Revised Manuscript Received on July 22, 2019.

* Correspondence Author

Tata Sutabri, Universitas Respati Indonesia, Indonesia. E-mail: tata.sutabri@gmail.com

R. Pandi Selvam, Assistant Professor \& Head, PG Department of Computer Science, Ananda College, Devakottai, India. E-mail: pandiselvamraman@gmail.com

K. Shankar*, Department of Computer Applications, Alagappa University, Karaikudi, India. E-mail: shankarcrypto@gmail.com

Phong Thanh Nguyen*, Department of Project Management, Ho Chi Minh City Open University, Vietnam. E-mail: phong.nt@ou.edu.vn

Wahidah Hashim, Institute of Informatics and Computing Energy, Universiti Tenaga Nasional, Malaysia.

Andino Maseleno, Institute of Informatics and Computing Energy, Universiti Tenaga Nasional, Malaysia. to expect to get exact outcomes in the underlying phase of research. The reason is each human have distinctive insusceptibility power and stamina. There are numerous diagnostics focus who are completely reliant on the supplies which are completely founded on AI. So as to support this procedure it is important to gather the continuous patient's information from various clinics, states and nations. With the goal that it will be valuable for around the world.

\section{UNDERSTANDING ARTIFICIAL INTELLIGENCE}

While starting any research in Machine learning, it is very important to understand how artificial intelligence is supporting the research approach. It is also important to understand the AI vocabulary. Different countries may have different terms for same disease. The term artificial intelligence refers to make a computer capable to take the correct decision to perform a task depends on the diagnose.

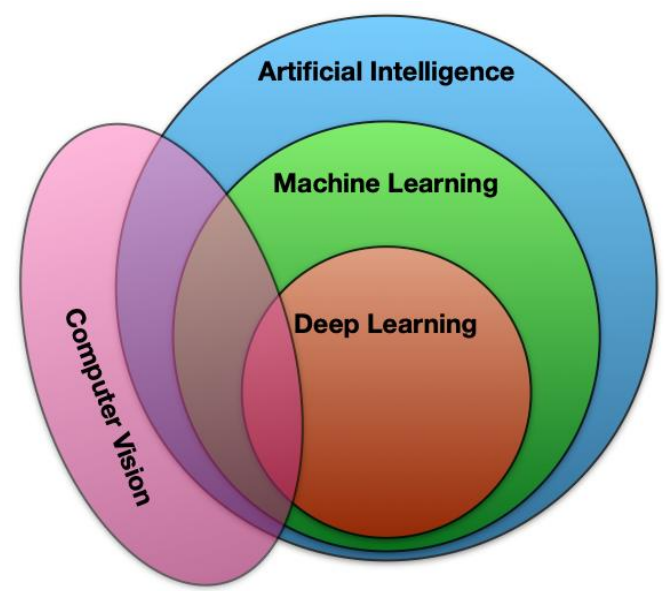

Figure 1. A sample Venn Diagram of Machine Learning Artificial Intelligence system

\section{MACHINE LEARNING}

The term machine learning is one of the most important term of artificial intelligence. It means make a computer system which learns every day on the basis of datasets provided day by day. It also saves patterns which helps the computer system to make the correct decision. This is also known as deep learning. 


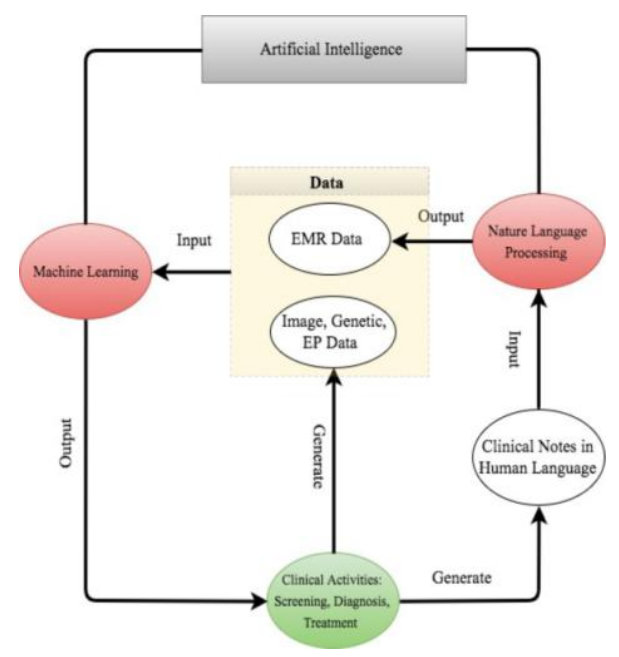

Figure 2: Machine Learning General Cycle

The feature extraction algorithms plays the most important part in machine learning and such system helps to make clinical datasets for future research of current research.

\section{NEURAL NETWORKS}

The neural networks research is very similar to the brain of a human, its helps to recognize patterns and extract features to know more about the data. Then it predicts the result which helps to diagnose the disease.

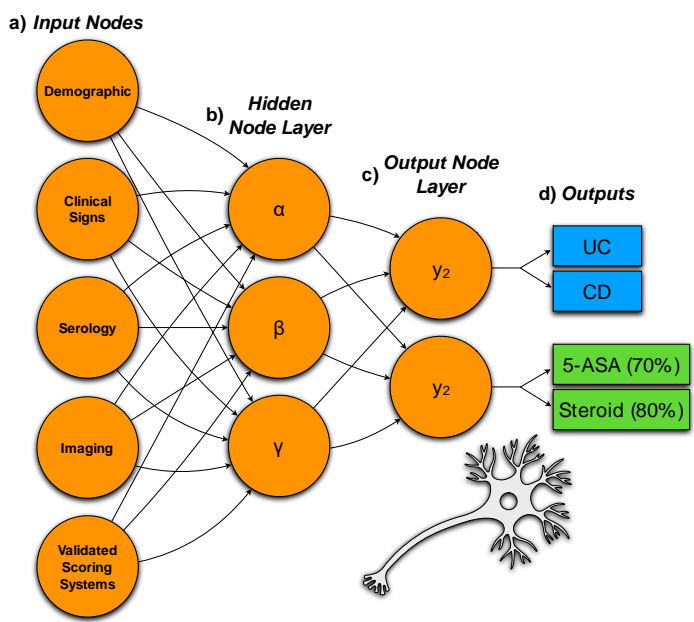

Figure 3: Neural Network with Deep Learning Example

Exampled here are the anticipated conclusion of UC or CD (from yield layer y1), a parallel order. Notwithstanding, these systems can likewise be utilized to anticipate quantitative outcome, for example the level of symptomatic improvement to a clinical treatment, for example 5-ASA and corticosteroid (yield y2).

\begin{tabular}{|c|c|c|c|c|}
\hline Retail & Marketing & Healthcare & Telco & Finance \\
\hline $\begin{array}{l}\text { - Demmand forécasting } \\
\text { - Supply chain } \\
\text { optimization } \\
\text { - Pricing optimization } \\
\text { - Market segmentation } \\
\text { and targeting } \\
\text { - Recommendations }\end{array}$ & $\begin{array}{l}\text { - Recommentation } \\
\text { engines \& targeting } \\
\text { - Customer } 360 \\
\text { - Click-stream } \\
\text { analysis } \\
\text { - Social media } \\
\text { analysis } \\
\text { - Ad optimization }\end{array}$ & $\begin{array}{l}\text { - Predicting Patient } \\
\text { Disease Risk } \\
\text { - Diagnostics and } \\
\text { Alerts } \\
\text { - Fraud }\end{array}$ & $\begin{array}{l}\text { - Customer chum } \\
\text { - System log analysis } \\
\text { - Anomaly detection } \\
\text { - Preventative } \\
\text { maintenance } \\
\text { - Smart meter analysis }\end{array}$ & $\begin{array}{l}\text { - Risk Anáalytics } \\
\text { - Customer } 360 \\
\text { - Fraud } \\
\text { - Credit scoring }\end{array}$ \\
\hline
\end{tabular}

This information could then be mulled over among specialist and patient allowing an information educated choice. By and by AI and man-made reasoning is playing one of the most significant job in analyze numerous hereditary and non hereditary illness. With the goal that the fast creations in AI can spare a large number of life's as it can analyze the beginning period of numerous genuine infections. In this exploration the datasets for such sicknesses is examined and it will be investigated that how such profound AI will effect to a human life. The issue with such procedure is that it is absurd to expect to get precise outcomes in the underlying phase of research. The reason is each human have diverse invulnerability power and stamina. There are numerous diagnostics focus who are completely reliant on the types of gear which are completely founded on AI. So as to support this procedure it is important to gather the continuous patient's information from various medical clinics, states and nations. With the goal that it will be gainful for around the world.

The legislature in numerous nations is advancing such exercises with the goal that it helps in more noteworthy improvement in such systems. The utilization of PC and man-made reasoning conclusions rapidly and in an ideal manner. The past looks into datasets improves the outcome. Gaining from past outcomes or datasets and improvement in analyze is known as profound learning. Profound learning is one of the most delightful piece of AI. For instance, simply accept a recently begun research in $\mathrm{AI}$ is as another conceived youngster.
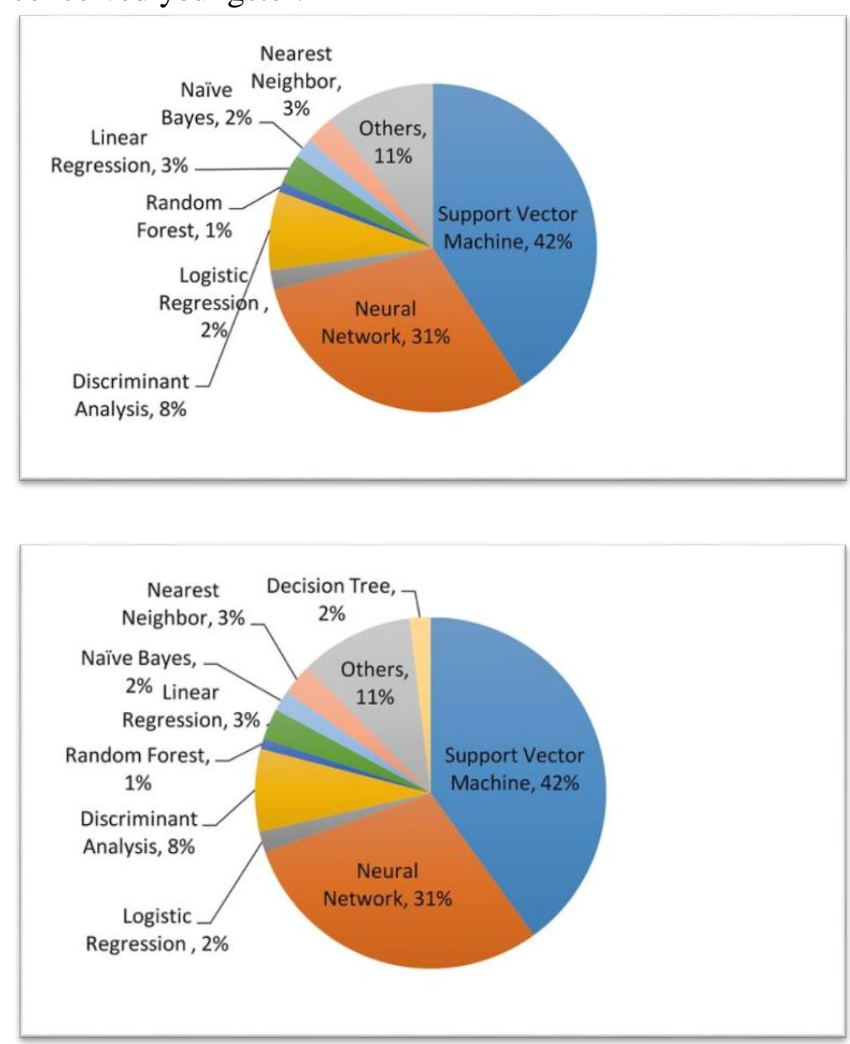

Figure 4: Machine Learning Algorithms Analysis

Published By:

Blue Eyes Intelligence Engineering \& Sciences Publication

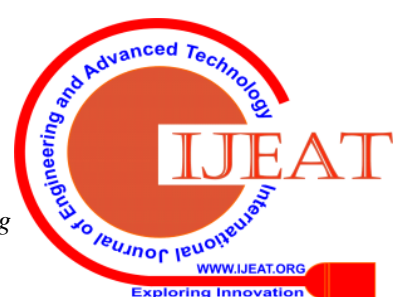


At first simply like another conceived kid the AI look into in introductory stage knows nothing. However, subsequent to giving datasets step by step, it will begin perform better and furthermore will give the better outcomes. The PC framework who are utilizing AI framework are skilled to process and create a major measure of restorative information additionally they can deliver the ongoing outcomes in like manner. Which is unimaginable by a doctor? The issue with such method is that it is crazy to hope to get definite results in the fundamental period of research. The reason is every human have unmistakable invulnerability power and stamina. There are various diagnostics center who are totally dependent around the provisions which are totally established on AI. To help this method it is imperative to assemble the consistent patient's data from different facilities, states and countries. With the objective that it will be profitable for around the globe.

While beginning any exploration in Machine learning, it is imperative to see how computerized reasoning is supporting the examination approach. It is likewise imperative to comprehend the AI jargon. Various nations may have various terms for same ailment. The term man-made consciousness alludes to make a PC fit to take the right choice to play out an assignment relies upon the analyze.

\section{CONCLUSION AND FUTURE SCOPE}

The future of AI techniques will directly put an large impact on the field of medical research. The last being the place we were to honestly depend on this innovation and overlook the clinical thinking we as a whole gone through years preparing for. Legitimately, who might assume liability for the patients that are erroneously analyzed by automated diagnostics, the malignancy that is missed, for example? While innovative development has made preparing incredible computational models to man-made consciousness a doable assignment, a powerlessness to encourage fake mankind features the need of embracing an AI-helped practice, rather than an AI-driven one. The previous researches datasets helps to improve the result. Learning from previous results or datasets and improvement in diagnose is known as deep learning. Deep learning is one of the most beautiful part of machine learning. For example, just assume a newly started research in machine learning is as a new born child. We checked on the inspiration of utilizing AI in social insurance, introduced the different medicinal services information that AI has broke down and overviewed the significant illness types that AI has been sent. We at that point talked about in subtleties the two noteworthy classifications of AI gadgets: ML and NLP. For ML, we concentrated on the two most prominent traditional procedures: SVM and neural system, just as the cutting edge profound learning strategy. We at that point overviewed the three noteworthy classifications of AI applications in stroke care. A fruitful AI framework must have the ML segment for taking care of organized information (pictures, EP information, hereditary information) and the NLP segment for mining unstructured writings. The advanced calculations at that point should be prepared through medicinal services information before the framework can help doctors with infection analysis and treatment recommendations.

\section{ACKNOWLEDGMENT}

This article has been written with financial support of RUSA-Phase 2.0 grant sanctioned vide Letter No. F. 24-51/2014-U, Policy (TNMulti-Gen), Dept. of Edn. Govt. of India, Dt. 09.10.2018.

\section{REFERENCES}

1. AIMI. RSNA 2017: Rads who use AI will replace rads who don't. 2017 [cited; Available from: https://aimi.stanford.edu/about/news/rsna-2017-rads-who-use-ai-will-rep lace-rads-who-don-t

2. Baruch J. Steer driverless cars towards full automation. Nature 2016;536:127.

3. Byrne MF, Chapados N, Soudan F, et al. Real-time differentiation of adenomatous and hyperplastic diminutive colorectal polyps during analysis of unaltered videos of standard colonoscopy using a deep learning model. Gut 2017.

4. Carey WD. How should a patient with an isolated GGT elevation be evaluated? Cleve Clin J Med 2000;67:315-6.

5. Cellan-Jones R. Stephen Hawking warns artificial intelligence could end mankind. BBC News 2014.

6. Dey A. Machine Learning Algorithms: A Review. IJCSIT 2016;7:1174-1179.

7. East JE, Rees CJ. Making optical biopsy a clinical reality in colonoscopy. Lancet Gastroenterol Hepatol 2018;3:10-12.

8. Farmer A, Ruffle J. Irritable bowel syndrome: enigmatic for doctors, problematic for patients. Trends in Urology \& Men's Health 2017;8:13-16.

9. Farmer AD, Ruffle JK. Irritable bowel syndrome. Hamdan Medical Journal 2015;8.

10. Goodfellow I, Bengio Y, Courville A. Deep Learning: MIT Press; 2017.

11. Herman J, Pokkunuri V, Braham L, et al. Gender distribution in irritable bowel syndrome is proportional to the severity of constipation relative to diarrhea. Gend Med 2010;7:240-6 